work than elaborately fitted laboratories. Desk work must be lethroned to a large extent and the pupils be given more time in the open air.

The exhibition of home-made apparatus was not so good as usual this year. Judging from the remarks of many teachers present at the conference, this exhibition has in previous years been regarded as one of the most helpful of the items on the programme of events, and Dr. Kimmins, to whose energy the success of the conferences is due, should develop this side of the annual meetings as largely as possible in future.

A. T. Simmons.

\section{A NEW RANGE-FINDER.'}

THE instrument designed by Prof. Forbes is intended only for use with rifle fire. It is not suitable for long-range artillery, or for the Navy. This infantry type is by far the most difficult to produce, because, in addition to accuracy, extreme portability is an essential feature. At the same time, the infantry are more in need of some addition to their present resources than any one else, and the urgent need of such an instrument has been proclaimed and re-echoed by all our officers who have returned from the war in South Africa.

All methods of optically measuring the distance of an in. accessible object depend on using a base of known length, which must be measured on the grourid, or else be part of the instrument. In the latter case the instrument can usually be worked by one man, who can find the distance without changing his position. This class of instrument is sometimes spoken of as short-base range-finders. Numerous patents for such instruments have been applied for; but the difficulties in the way of ensuring accuracy are so great that only one type has ever been perfectar and generally used. The Barr and $\mathrm{St}_{2}$ oud range-finder has been adopted by the Navy with most satisfactory results, and this has proved the fact that a short base (4 feet) is not inconsistent with accuracy. For the use of infantry, however, where extreme probability, and accuracy, and suitability for ill-defined objects, such as men, bushes, rocks, \&c., are essentials, this is an unsuitable instrument.

In the Barr and Stroud instrument the two images of a distant object are seen with one eye, hence the object appears to be double until the micrometer arrangement has been so moved as to make a coincidence of the two images, when the

scale reading of the micrometer gives the distance directly. Now in naval work, for which this instrument is made, a ship, or its mast or funnel, is very sharp against the sky, and the coincidence can easily be made; but this method is almost valueless in the field. A bush, or a rock, or a man is an object so ill-defined, especially against certain backgrounds, that in attempting to make a coincidence you may move one picture in the telescope over the other for a considerable angle before you are sure that it is double. The difficulty has been got over by Messrs. Carl Zeiss and Prof. Forbes, who make use of stereoscopic vision in the new range-finder.

The instrument consists of a tolding aluminium base, 6 feet in length, and a field glass. The base is a square tube hinged at its middle, and folds up to 3 feet 6 inches. Each half has at each end a doubly reflecting prism. The rays of light from a distant object strike the outer pair of these four prisms, are reflected at right angles along each tube, and are then reflected at the two middle prisms into the two telescopes of the binocular fixed to the base, in directions parallel to the original rays intercepted by the outer prisms. It is the measurement of the angle between these rays that tells the distance of the object looked at. This angle is measured by two vertical wires, one in each telescope, seen by the two eyes. One of the wires. is fixed, the other is moved by a micrometer-screw until the two

1 Abstract of a paper read before the Society of Arts on December 18, 1901, by Prof. George Forbes, F.R.S.

NO. I 68 I, vol. 65$]$ wires appear as one, while the object is seen distinctly. This gives the distance accurately to 2 per cent. even at 3000 yaras: But now stereoscopic vision comes in and gives far greater accuracy. The wire seems to stand out solid in space, and the slightest turn of the micrometex screw causes the wire to appear to be nearer or farther than the object looked at, and when the wire appears to be at exactly the same distance the micrometer reading gives the distance with an accuracy far greater than that attainable by observing the duplication of images on the retina.

This range-finder can be used in a variety of positions. The more steadily it is held the more accurate the result. A standing position is the least steady. When kneeling, using only half the base, the other half may be bent down at right angles, and so form a leg which serves as a rest on the ground. The most easy position is sitting with the elbows resting on the knees. Another steady position is lying flat on the ground facing the object (Fig. I). In every one of these positions you can take advantage of cover. Since the eyes are virtually at the extremities of the base, the observer may stand, sit, kneel, or lie behind a tree, bush, rock, ant-hill, horse, comrade, or waggon, and will not only be more able to work without sensation of danger, but without drawing the fire of the enemy on his comrades.

Lord Kitchener having expressed a desire to see the range- 
the debt-7500l. - in order that the debt of the College may be extinguished altogether.

AT a special meeting of the Court of the Victoria University, the recent movements to establish separate Universities in Liverpool, Manchester and Leeds were discussed. As the University College, Liverpool ; Owens College, Manchester; and the Yorkshire College are the three constituent colleges of the Victoria University, the establishment of the three proposed Universities would mean the disruption of the present federated University. The two alternatives which the Court had to consider were as follows :- " Having regard to the resolutions of the three constituent colleges of the University, the question for decision must be whether $(a)$ the three colleges are to remain as constituent colleges of the University; or whether $(b)$ there should be a separate University in Liverpool and a 'University in Manchester without liability to admit or to remain in association with any other college,' and also a 'University established having its seat in Leeds." "' The latter view was accepted, and a committee was appointed to consider the terms and conditions on which it should be carried into effect.

THE New York correspondent of the Morning Leader says that the gifts to education in the United States in Igor amount to more than $15,000,000 l$. Of this sum $9,000,000$. was contributed by three individuals. Mrs. Leland Sanford gave the magnificent sum of $6,000,000$. to the western University which bears her husband's name. Mr. John D. Rockefeller made an endowment of $\mathrm{I}, 000,000 \mathrm{l}$. for the law school in the University of Chicago, and Mr. Andrew Carnegie has given 2,000,000l. to found an institution for scientific research at Washington. Mrs. Leland Sanford's gift of $6,000,000 \%$. was in real estate and bonds and stocks. In making her gift Mrs. Sanford was actuated by the example of many wealthy persons in making bequests before their death in order to avoid possible will contests which might tie up the property for years. Mr. Carnegie's gift to endow research provides the United States with a fund which, wisely administered, will greatly strengthen university work in America and give an impetas to investigation which will have a profound influence upon the progress of the country.

THAT there is a widespread desire to mudify the traditional methods of teaching the subjects of the ordinary secondary school curriculum and to bring them more into harmony with the practical needs of present everyday life, is strikingly shown by the frequent discussions on the desirability of reform in the teaching of mathematics which have taken place in the last few months. One of the most recent of such discussions was that which followed an address by Mr. W. C. Fletcher, headmaster of Liverpool Institute, at the meeting of the Incorporated Association of Headmasters held in London last week. Mr. Fletcher moved the following resolution, which was eventually adopted : "That this Association desires to press upon the universities and other examining bodies the desirability of greater elasticity in their regulations as to mathematical teaching, and is of opinion that to insist upon adherence to the order of propositions in Euclid is mischievous." Mr. Fletcher said that six years' experience of teaching geometry has led him to believe that Euclid is a great hindrance to ninety-nine boys out of every hundred in training and knowledge. A great deal of damage is done by insistence, not only upon the particular method, but on the particular order, of Euclid. As the result of his experience he had re-written the first half of Euclid's first book, omitted the second book, and introduced two or three propositions about proportion, in this way forming an interesting, sound and coherent plan. The headmasters were so impressed with the value of Mr. Fletcher's remarks that they decided to have his speech printed and circulated among teachers.

THE position of the University of Birmingham was described by the Vice-Chancellor, Mr. Chamberlain, at the second annual Court of Governors held on January 8. On the occasion of the former annual meeting the fund raised for the purpose of the University amounted to $330,000 l$. ; it has now reached $420,000 l$. The Birmingham City Council has made a grant equal to a halfpenny in the pound on the borough rate, and this will provide about $5500 l$. per annum towards the ordinary maintenance of the University. The Staffordshire County Council has similarly identified itself with the aims of the University by making a grant of 500\%. a year for five years in aid of the School of Mining and Metallurgy. It is hoped that the example NO. I $68 \mathrm{I}$, VOL. 65$]$ will be followed by the county councils of Worcestershire, Warwickshire and Shropshire, and that the annual contributions from all these sources will amount to at least 7000 l. per annum. With the practical assurance of this income, a sum of $300,000 l$. is available for the new buildings of the University. It is estimated that the buildings contemplated cannot be erected and equipped for a less sum than a million sterling. Out of the ten departmental blocks of the University, three are to be commenced, in the first instance, to accommodate the schools of mining and metallurgy, and of civil, mechanical and electrical engineering. A University Hall will also be erected. While the University buildings are being erected, the Mason College must be extended in some way and its equipment increased, in order to accommodate the additional students who have entered since the University was founded. For this purpose $10,000 l$. will be required, and Mr. Chamberlain announced that $6000 \%$. had already been subscribed.

\section{SCIENTIFIC SERIALS.}

Annals of Mathematics (July and October, 190r).-Concerning Du Bois Reymond's two relative integrability theorems. The two theorems considered by E. H. Moore are, (I) a continuous function of (properly) integrable functions is integrable ; (2) an integrable function of an integrable function is integrable. (I) was announced in 1880 and a proof published two years later (Math. Ann., vols. xvi. and xx.). In connection with this proof (2) was announced. Dr. Moore in this note shows, by means of a simple example, that (2) is not true. Reference is made to a proof of ( $\mathrm{I}$ ) by Dini with an extension which is not applicable to the general case, but Dr. Moore extends Du Bois Reymond's general proof (1882).-P. Saurel, on a theorem of kinematics, gives an elementary demonstration of the well-known theorem that every displacement of a rigid body is equivalent to a rotation followed by a translation parallel to the axis of rotation. - The collineations of space which transform a non-degenerate quadric surface into itself, by Ruth G. Wood, discusses the $\infty^{6}$ collineations of space which transform the surface.-J. Westland contributes a note on multiply perfect numbers, with a view to determine all numbers of multiplicity 3 of the form $m=p_{1} a_{1} p_{2} \alpha_{2} p_{3}$ where $p_{1}, p_{2}, p_{3}$ are three distinct primes and $p_{1}<p_{2}<p_{3}$. The isoperimetrical problem on any surface, by J. K. Whittemore, gives a generalisation of the problem known to Pappus (see W. Thomson, "Popular Lectures and Addresses," vol. ii. p. 578). He solves Pappus's problem by the calculus of variations, and then: solves, by an apparently novel method, the problem "Find a curve, $v=\phi(u)$, joining the two given points $\left(u_{0}, v_{0}\right)$ and $\left(u_{1}, v_{1}\right)$ having a given length $\mathrm{L}$, and such that the area of the portion of the surface between the two curves, $v=f(u)$ and $v=\phi(u)$, shall be a maximum."-On a surface of the sixth order which is touched by the axes of all screws reciprocal to three given screws, by E. W. Hyde, has for its main object the determination and discussion of the envelope of a certain conicoid, which is touched by the axes of all screws of a certain system, so enabling one to grasp the nature of the system. The surface possesses other features of interest. The paper is illustrated with diagrams.-D. Sintsof, in a note sur l'évaluation d'une intégrale définie, discusses a previous note by $M$. Pell (evaluation of a definite integral, Annals (2), tome I, No. 3).-The October number opens with a lengthy article (18 pp.) on the convergence of the continued fraction of Gauss and other continued fractions, by E. B. Van Vleck. Numerous references are given.-M. B. Porter supplies a short note on the differentiation of an infinite series term by term. - A note on geodesic circles, by J. K. Whittemore, discusses these circles in Bianchi's sense, viz. their definition is the locus of a point on a surface at a constant geodesic distance from a fixed point of the surface ("Vorlesungen über Differ. entialgeometrie," p. I60). Darboux ("Théorie Générale des Surfaces," vol. iii. p. 15 I) calls such a circle a curve of constant geodesic curvature. Mr. Whittemore gives three theoremsthe first is, If, on a surface, there exists a family of concentric geodesic circles, such that the geodesic curvature of each curve of the family is constant, then the total curvature of the surface is constant along each curve of the family, and the surface is applicable to a surface of revolution, so that the geodesic circles fall on the circles of latitude of this surface.-Prof. Osgood gives a note on the functions defined by infinite series whose terms are analytic ffunctions of a complex variable, with cor- 